Check for updates

Cite this: New J. Chem., 2017, 41,13918

Received 15th September 2017, Accepted 9th October 2017

DOI: $10.1039 / c 7 n j 03526 h$

rsc.li/njc

\section{Water-stable [Ni(salen)]-type electrode material based on phenylazosubstituted salicylic aldehyde imine ligand $\dagger$}

\author{
Anatoly A. Vereschagin, (D) Vladimir V. Sizov, (D) Petr S. Vlasov, Elena V. Alekseeva, \\ Alexander S. Konev (D) and Oleg V. Levin (D)*
}

A novel electrode material was prepared by electrochemical oxidation of $\left[4,4^{\prime}\right.$-phenylazo-2, $2^{\prime}$ (ethylenediimino- $\kappa^{2} N$-methyl)diphenolate- $\kappa^{2} O$ ]nickel, a [Ni(॥)(salen)]-type complex, in chlorinated solvent. The chemical structure of the material was explored by FTIR, NMR and XPS techniques to determine the main components of the material and the nature of the linkage between them. The morphology of the material films was explored by SEM analysis. The electrochemical properties of the new material were studied by a set of voltammetric methods and an unusual stability of the material in aqueous medium was observed.

\section{Introduction}

Polymeric nickel complexes, $[\mathrm{Ni}(\text { Rsalen })]_{n}$, with tetradentate ligands based on the organic framework of salicylic aldehyde ethylenediimine, often referred to as salen, are widely explored as prospective materials for energy storage ${ }^{1-6}$ electroanalytical ${ }^{7-9}$ and optoelectronic ${ }^{10}$ applications. In particular, [Ni(Rsalen)]n materials bearing $\mathrm{Br}-, \mathrm{Cl}-, \mathrm{Me}_{-},{ }^{11,12}$ and $\mathrm{MeO}^{-13-15}$ substituents in the ortho-position and alkyl ${ }^{6,20,21}$ and $\mathrm{Br}^{-19}$ substituents in the para-position of the phenyl ring with respect to the phenolate group have been extensively studied by other researchers. Typically, substituents in the ortho-position do not prevent the formation of polymeric material, while substituents in the para-position have been shown to prevent polymerization. ${ }^{6,20,21}$ The advantages of these materials include low cost, easy preparation and low toxicity combined with affordable relevant electrochemical characteristics. However, low stability in aqueous media ${ }^{16,17}$ imposes limitations on the practical application of these materials.

To allow rational design of stable [Ni(salen)]-based materials, it is necessary to understand the structure of the macromolecular compounds of these materials. At present, the important question of the nature of the linkage that connects starting monomers is rather disputable. Some researchers (Timonov, 1998; Brett, 2015)

198504, St. Petersburg State University, Institute of Chemistry, Universitetskii pr. 26, Peterhof, St., Petersburg, Russian Federation.E-mail: o.levin@spbu.ru, nibiru@yandex.ru

$\dagger$ Electronic supplementary information (ESI) available: Additional data on electrochemical and XPS studies, computational data, X-ray CIF-file. CCDC 1543618. For ESI and crystallographic data in CIF or other electronic format see DOI: $10.1039 / \mathrm{c} 7 \mathrm{nj} 03526 \mathrm{~h}$ postulate the formation of intermolecular metal-phenyl $\pi$-stacks ${ }^{17-19}$ or metal-metal bonds ${ }^{20}$ in the starting monomers ("stacked polymer"). Many others (Goldsby, 1989; Audebert, 1992; Hillman, 1997) postulate that this linkage is a covalent $\mathrm{C}-\mathrm{C}$ bond connecting phenyl rings in monomeric fragments (classical polymer) ${ }^{16,21-23} \mathrm{~A}$ hybrid model (Dahm, 1996) combining both types of linkage has also been proposed. ${ }^{24}$ The stacked-polymer model is based on the observation of anisotropic conductivity in polymeric nickel salen complexes. ${ }^{25}$ The strongest evidence for the classic polymer model with formation of a covalent C-C bond between monomeric fragments of nickel salen complex has been reported in the work of Audebert et al; the group demonstrated the formation of biphenyl-4,4'-dicarbaldehyde derivatives upon extensive hydrolysis of the polymeric material. ${ }^{16}$ The hybrid model is based on the observation of two waves in the process of oxidative electropolymerization of [Ni(salen)] with overall detraction of three electrons per monomer unit: the first wave results in the stacking of monomer molecules with $\mathrm{Ni}^{\mathrm{III}}-\mathrm{Ph}$ stacks formation (one-electron process of $\mathrm{Ni}^{\mathrm{iI}}$ to $\mathrm{Ni}^{\mathrm{III}}$ conversion), while the second wave corresponds to covalent sewing of the monomers in the stacked material $(-2 \mathrm{H} \cdot$, twoelectron process). Unsuccessful attempts for the direct identification of $\mathrm{Ni}^{\mathrm{III}}$ by NMR spectroscopy ${ }^{26-29}$ have strengthened the hypothesis that the formation of covalent $\mathrm{C}-\mathrm{C}$ bonds is the exclusive cause for the formation of polymer films. However, several reports on EPR spectroscopy demonstrated the possibility of a $\mathrm{Ni}^{\mathrm{II}}$-phenoxyl radical to $\mathrm{Ni}^{\mathrm{iII}}$-phenolate transition for [Ni(salen)] complexes in highly coordinating solvents or in the presence of coordinating additives like pyridine. ${ }^{30-35}$ The same transition was observed at low temperature. ${ }^{36}$

An additional pro-covalent bond argument consists of prevention of the polymerization process of the nickel salen 


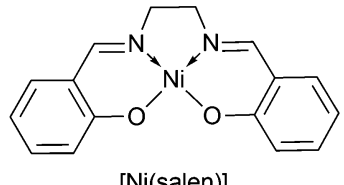

[Ni(salen)]
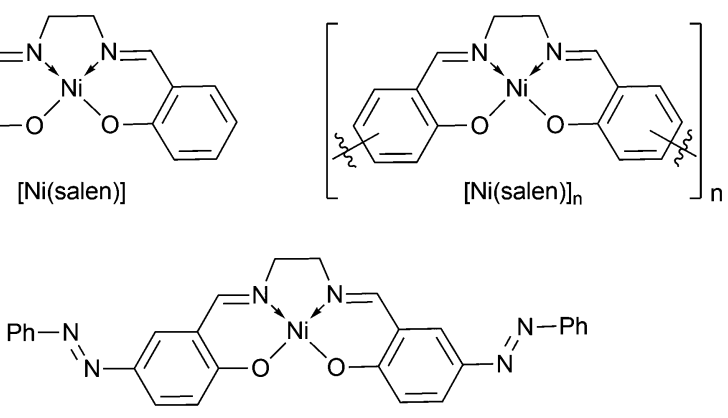

[Ni(Phazosalen)]

Scheme 1 Structures of monomeric nickel complexes [Ni(salen)] $\left[\mathrm{Ni}(\right.$ Phazosalen) $]$ and polymer $[\mathrm{Ni}(\text { salen })]_{n}$.

complex when position 5 ( $p$-position respective to oxygen atom) in the phenyl ring is blocked by a tert-butyl ${ }^{20}$ or methyl ${ }^{6,21}$ substituent. However, Timonov et al. reported the formation of polymeric materials upon oxidation of nickel complex with 5-bromine substituted salen ligand. ${ }^{19}$ However, the presence of bromine in the resulting product was not entirely proved, while the possibility of oxidative coupling of halogen substituted phenyl rings cannot be completely ruled out. ${ }^{20}$ In addition, in the case of 5-tert-butyl or 5-methyl substituted nickel salen complexes, polymerization might be precluded due to the steric hindrance for stacking induced by the alkyl groups and not by the blockage of the $p$-position for the formation of the covalent $\mathrm{C}-\mathrm{C}$ bond. Therefore, to address the question of the possibility of "stacked polymer" formation in case of nickel complexes with the 5-substituted salen ligand, a planar and inert substituent is required. In the present study, we suggest the phenylazo group as a model substituent, report our results on electrooxidation of nickel phenylazosalen complex [Ni(Phazosalen)] (Scheme 1) and discuss the structure, electrochemical properties and stability of the resulting material.

\section{Results and discussion}

The starting nickel complex [Ni(Phazosalen)] was obtained by a known procedure via azo-coupling of phenyldiazonium chloride with salicylic aldehyde, followed by condensation of the resulting phenylazo-substituted aldehyde with ethylene diamine and subsequent metalation with nickel acetate. ${ }^{37}$

[Ni(Phazosalen)] was electrochemically active in the $0.4-$ $1.4 \mathrm{~V}$ range, showing an irreversible oxidation peak at $1.26 \mathrm{~V}$, followed by an intense oxidation wave at higher potentials. To check the possibility of polymerization of [Ni(Phazosalen)] and to optimize the polymerization conditions, we performed repetitive voltage cycling with variable upper potential boundary (ESI, $\uparrow$ Fig. SI1). The formation of polymer film was not observed when the monomer complex was subjected to voltage cycling in 0.4-1.1 V. Extension of the anodic range of the potential window (from $1.2 \mathrm{~V}$ to no more than $1.4 \mathrm{~V}$ ) resulted in formation and steady growth of new anodic and cathodic peaks. This led to the formation of a new electroactive material on the electrode, arbitrarily denoted below as $[\mathrm{Ni}(\text { Phazosalen })]_{n}$ (ESI, $\dagger$ Fig. SI1).

It is known ${ }^{23,38}$ that the stability of nickel-salen based electrode materials drastically deteriorates if the material is kept at high anodic voltage. The same effect was observed when $[\mathrm{Ni}(\text { Phazosalen })]_{n}$ was deposited from solution by voltage cycling in $0.4-1.5 \mathrm{~V}$ (ESI, $\dagger$ Fig. SI1e). The film formed during the first few cycles lost the electrochemical activity almost entirely by the 10th cycle. For this reason, deposition of the new electrode material, [Ni(Phazosalen) $]_{n}$, from [Ni(Phazosalen)] was performed in potentiostatic mode at the onset of [Ni(Phazosalen)] oxidation (1.2 V vs. $\mathrm{Ag} \mid \mathrm{AgCl})$ in all the experiments discussed below. Unlike cycling mode, the potentiostatic mode of electrochemical deposition allows for the control of the amount of charge used for polymer formation, ensuring reproducibility of the properties of the deposited films. Oxidative electrochemical deposition was performed from $1 \mathrm{mM}$ solution of the starting complex in 1,2-dichloroethane (DCE) containing 0.1 $\mathrm{M} \mathrm{Bu}_{4} \mathrm{~N}^{+} \mathrm{BF}_{4}{ }^{-}$as the supporting electrolyte (ESI, $\dagger$ Fig. SI2), and the film thickness was controlled by maintaining a charge of $57 \mathrm{mC} \mathrm{cm} \mathrm{cm}^{-2}$. Acetonitrile and propylene carbonate, usual solvents for electropolymerization of [Ni(salen)] complexes, could not be used due to very low solubility of $[\mathrm{Ni}($ Phazosalen $)]$ in these solvents. Hence, the commonly used $\mathrm{Et}_{4} \mathrm{~N}^{+} \mathrm{BF}_{4}{ }^{-}$was substituted for $\mathrm{Bu}_{4} \mathrm{~N}^{+} \mathrm{BF}_{4}^{-}$to improve the solubility.

The obtained material is electrochemically active and stable in the range of $0-1.2 \mathrm{~V}$, where two redox processes occur at $E_{1 / 2}=0.85 \mathrm{~V}\left(\mathrm{CH}_{3} \mathrm{CN} / 0.1 \mathrm{M} \mathrm{Et}_{4} \mathrm{~N}^{+} \mathrm{BF}_{4}{ }^{-}\right)$and $E_{1 / 2}>1.1 \mathrm{~V}$ (Fig. 1). The value of the first redox potential is quite close to the halfwave potential of the oxidation of the benchmark material, $[\mathrm{Ni}(\text { salen })]_{n}(0.9 \mathrm{~V})$. The redox processes in $[\mathrm{Ni}(\text { Phazosalen })]_{n}$ reach equilibrium by the 10th cycle of CVA and no loss in electrochemical activity is observed up to the 50th cycle. The Coulombic efficiency of this process is about 95\%. The anodic cut-off potential of $1.2 \mathrm{~V}$ is not sufficient to fully observe the second oxidation process on the voltammogram. However, application of higher voltage up to $1.4 \mathrm{~V}$ leads to the appearance of irreversible anodic current and results in degradation of the material and significant loss of its electroactivity: the charge drops to $65 \%$ of the initial value by the 27 th cycle.

For comparison, similar data for $[\mathrm{Ni}(\text { salen })]_{n}$ are presented in Fig. 2. It can be observed that the films of the latter demonstrate lower stability (the electrochemical activity of these films dropped by $30 \%$ during 50 cycles of voltage cycling). The Coulombic efficiency of the $[\mathrm{Ni}(\text { salen })]_{n}$ charge-discharge process does not exceed $90 \%$.

Electrochemical impedance spectroscopy (EIS) is known to be a reliable and informative method for studying the charge transport and storage in polymer films. Fig. 3 shows the complex plane impedance plots for $[\mathrm{Ni}(\text { Phazosalen })]_{n}$ and $[\mathrm{Ni}(\text { salen })]_{n}$ films constructed for the different potentials applied. The spectra of both polymers have a similar pattern. At high frequencies, semicircles are observed that correspond to RC element consisting of the double layer charging capacitance, $C_{\mathrm{dl}}$, and charge transfer resistance, $R_{\mathrm{ct}}$, related to the heterogeneous kinetic process of electrochemical oxidation. At lower frequencies, two linear 

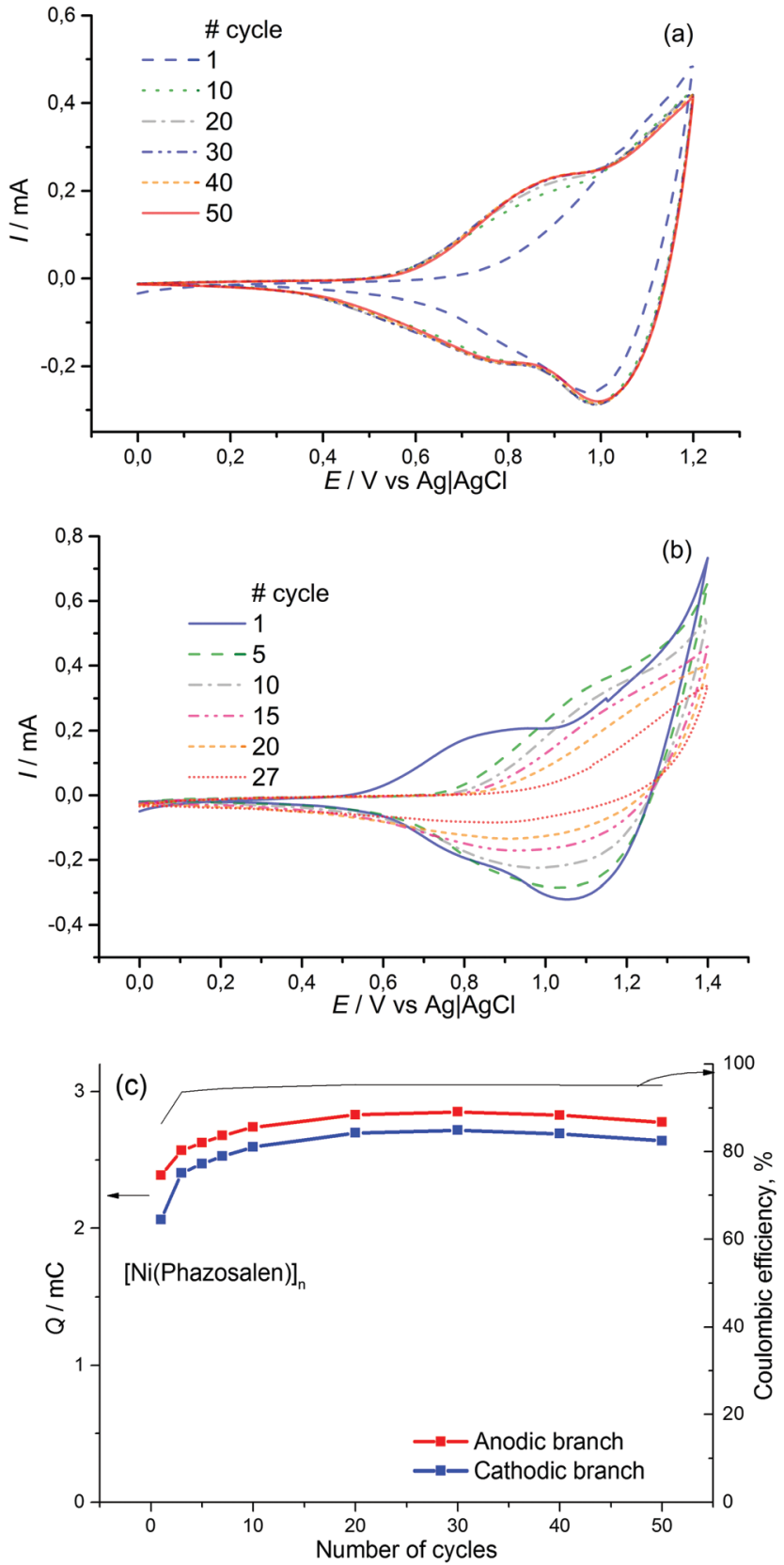

Fig. 1 CVA of [Ni(Phazosalen) $]_{n}$ at 0-1.2 V (a) and 0-1.4 V (b) films on ITO support in $0.1 \mathrm{M} \mathrm{Et}_{4} \mathrm{~N}^{+} \mathrm{BF}_{4}{ }^{-}$solution in acetonitrile, scan rate $50 \mathrm{mv} \mathrm{s}^{-1}$. (c) Charge integrated on the cathodic branches of CVA at 0-1.2 V and Coulombic efficiency of the charge-discharge process vs. cycle number.

regions of the curve are observed. The linear region of $45^{\circ}$ slope corresponds to the Warburg impedance, $Z_{\mathrm{W}}$, and is due to the diffusion of the counterions, while the linear region with slope close to $90^{\circ}$ corresponds to the low frequency capacitance, $C_{\mathrm{lf}}$, which arises from charging of the polymer film of finite thickness.

According to this pattern of the impedance spectra, they were simulated by a modified Randles-Ershler equivalent electric circuit. ${ }^{39}$ The elements of constant phase were introduced to the model instead of capacitance units to take into account

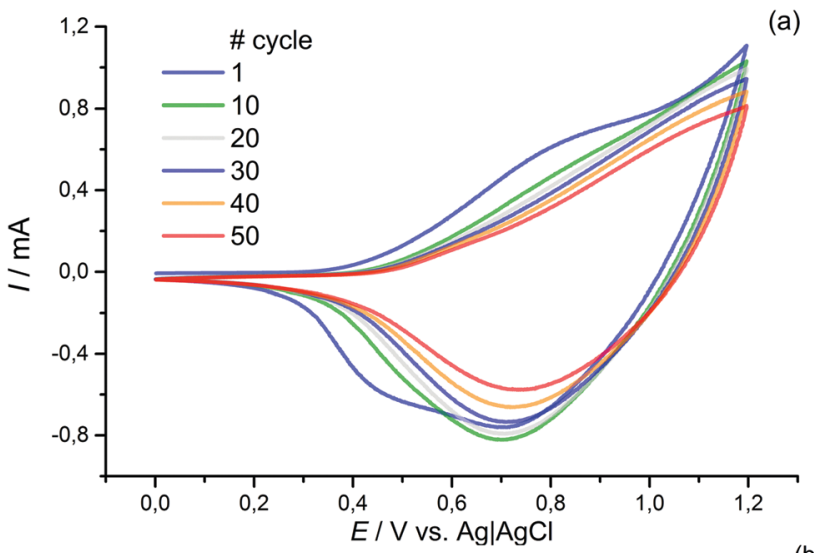

(b)

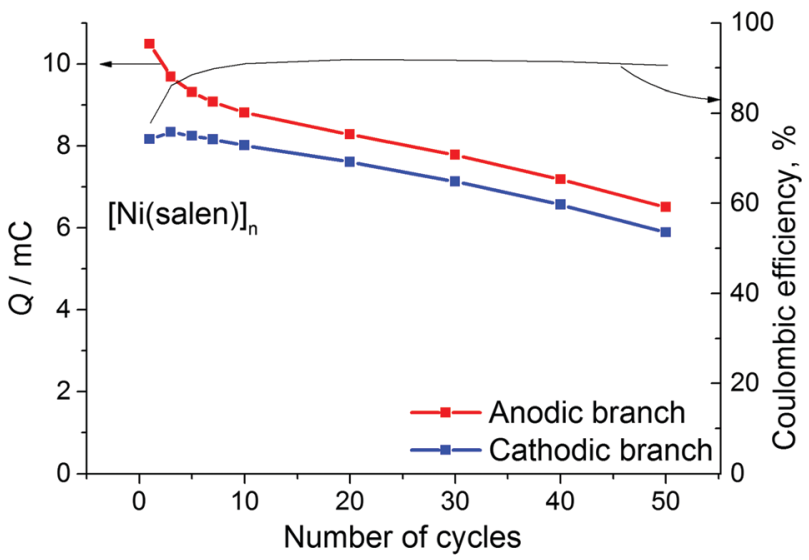

Fig. 2 CVA of [Ni(salen) $]_{n}$ film at 0-1.2 V (a) on ITO support in $0.1 \mathrm{M}$ $\mathrm{Et}_{4} \mathrm{~N}^{+} \mathrm{BF}_{4}^{-}$solution in acetonitrile, scan rate $50 \mathrm{mv} \mathrm{s}{ }^{-1}$. (b) Charge integrated on the cathodic branches of CVA and Coulombic efficiency of the charge-discharge process vs. cycle number.

non-uniform distribution of film thickness and their porous structure. The numerical values obtained after fitting of the spectra are shown in Fig. 4 and are summarized in Tables SIA1 and SIA2 (ESI $\dagger$ ). As can be observed from these data, both polymers demonstrate an increase in the Warburg coefficient $\sigma$ with increasing voltage, accompanied by a decrease in the charge transfer resistance. This testifies to the transition of the polymers to a more conducting state upon oxidation. It should be mentioned that $R_{\mathrm{ct}}$ of the [Ni(Phazosalen) $]_{n}$ film is one order of magnitude higher than $R_{\mathrm{ct}}$ of [Ni(salen) $]_{n}$, testifying to the slower kinetics of electrochemical transformations in the former polymer. At the same time, the Warburg constant of $\left[\mathrm{Ni}(\text { Phazosalen) }]_{n}\right.$ is several orders of magnitude higher than that of $[\mathrm{Ni}(\text { salen })]_{n}$. The effective diffusion coefficients, $D_{\mathrm{ef}}$, of the charge carriers within the studied films can be determined by using a constraint between the Warburg constant and the low-frequency capacity using the following equation: ${ }^{40}$

$$
D_{\text {ef }}=\frac{1}{2}\left(\frac{\left(t_{\mathrm{e}}^{2}+t_{\mathrm{m}}^{2}\right) L}{2 \sigma C_{\mathrm{lf}}}\right)^{2}
$$

where $t_{\mathrm{e}}$ and $t_{\mathrm{m}}$ are the transference numbers of electrons and counterions, respectively; $L$ is the film thickness. However, the 

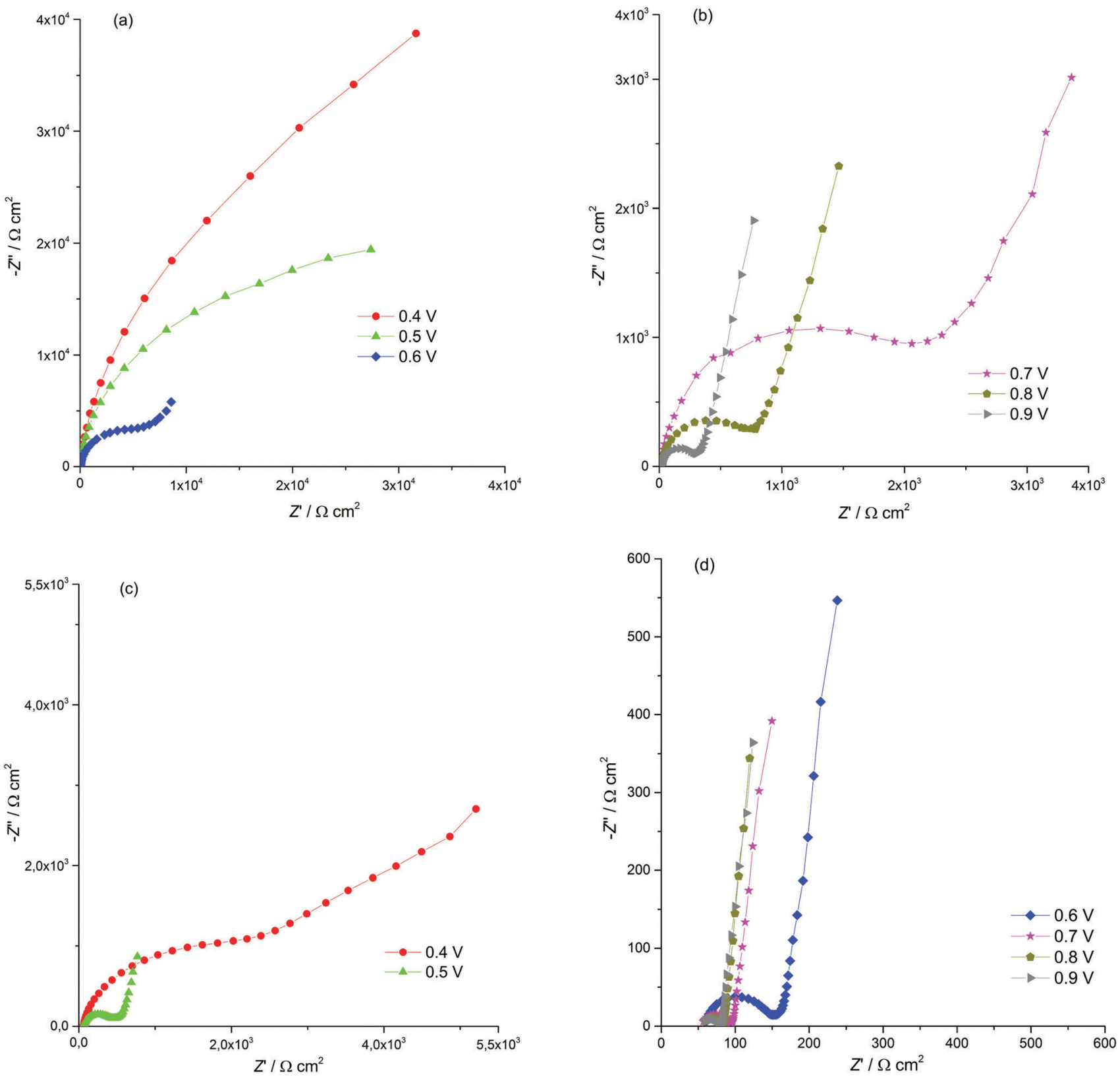

Fig. 3 Nyquist plots for the ITO electrode coated with [Ni(Phazosalen) $]_{n}$ (a and b) and [Ni(salen) $]_{n}$ (c and d) films in $0.1 \mathrm{M}(\mathrm{TEA}) \mathrm{BF}_{4}$, in acetonitrile, for different potentials applied.

uncertainty in the film thickness forces us to use the $D_{\text {ef }} / L^{2}$ parameter to characterize the diffusion rate. This parameter is about an order of magnitude lower for the [Ni(Phazosalen) $]_{n}$ film than for the $\left[\mathrm{Ni}(\text { salen) }]_{n}\right.$ film (Fig. 4(d)). Assuming that the thickness of the $[\mathrm{Ni}(\text { Phazosalen })]_{n}$ film is not higher than that of the $[\mathrm{Ni}(\mathrm{salen})]_{n}$ film, we can conclude that the diffusion of the charge carriers in the $[\mathrm{Ni}(\text { Phazosalen })]_{n}$ polymer is slower than the diffusion in $[\mathrm{Ni}(\text { salen })]_{n}$.

Qualitative elemental analysis of $[\mathrm{Ni}(\text { Phazosalen })]_{n}$ was performed using the XPS technique. Thus, a characteristic $\mathrm{Ni}$ atom signal was observed as a pair of $2 \mathrm{p}_{3 / 2}$ and $2 \mathrm{p}_{1 / 2}$ peaks at 854.6 and $871.9 \mathrm{eV}$ (Fig. SI4, ESI $\dagger$ ), while signals of $\mathrm{N}$ and $\mathrm{O}$ atoms were observed at 399.7 and $530.5 \mathrm{eV}$, respectively
(Fig. SI5 and S6, ESI $\dagger$ ). The peaks positions are slightly (0.1-0.4 eV) shifted to higher energies compared to the monomer complex, reflecting the increase in binding energy of core electrons upon oxidative polymerization (Table 1). The satellite signals were not observed in the range of signals for $\mathrm{Ni} 2 \mathrm{p}$ electrons in both [Ni(Phazosalen)] and [Ni(Phazosalen)]n. According to literature reports, ${ }^{41,42}$ this testifies to the planar structure of $\mathrm{Ni}$ complexes in both cases. Interestingly, the chemical shift of $\mathrm{Ni}, \mathrm{N}$ and $\mathrm{O}$ atoms $\left(2 \mathrm{p}_{3 / 2(1 / 2)}, 1 \mathrm{~s}\right.$ and $1 \mathrm{~s}$, respectively) upon polymerization of [Ni(salen)] is significantly larger than in the case of [Ni(Phazosalen)] (0.6-0.7 vs. $0.1-0.4 \mathrm{eV})$. This could testify to the existence of different modes of connection of the monomer units in the respective polymers, with 

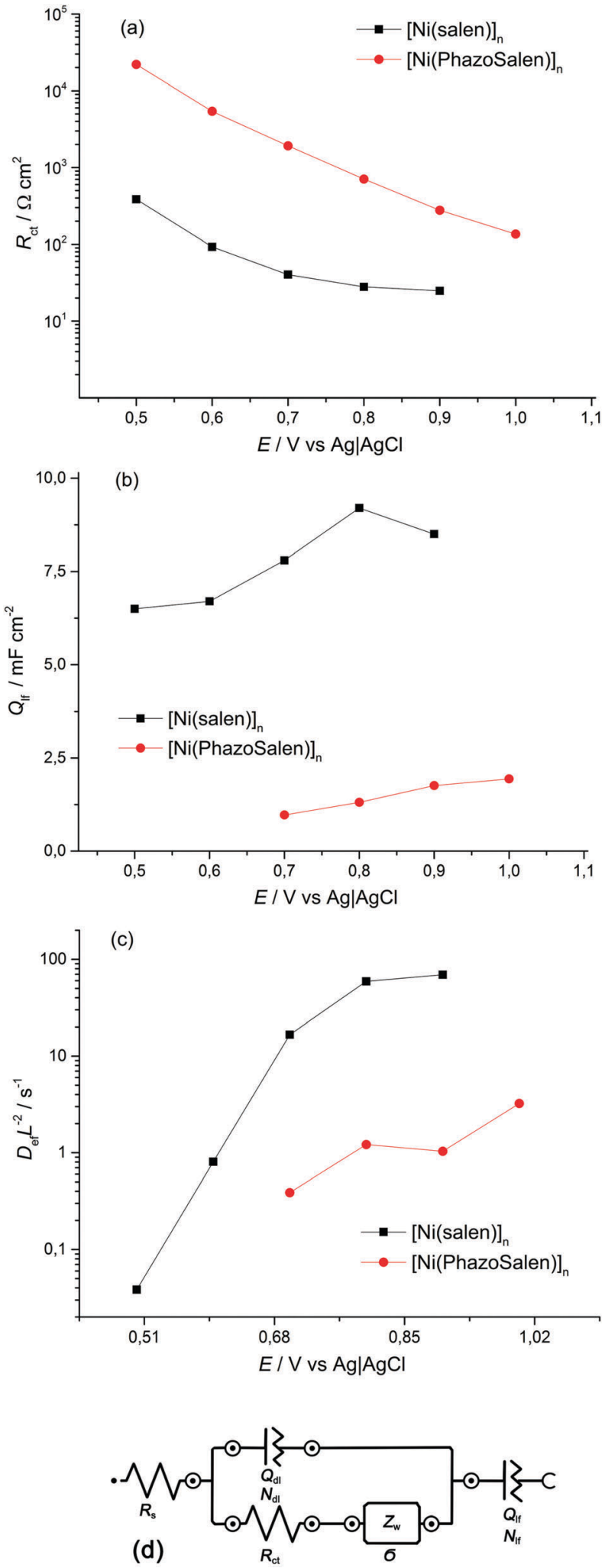

Fig. 4 Curves of (a) the charge transfer resistance change, (b) the low frequency capacitance change and (c) the diffusion parameter change with potential for the ITO electrode coated with the $\left[\mathrm{Ni}(\text { Phazosalen) }]_{n}\right.$ and $\left[\mathrm{Ni}(\text { salen) }]_{n}\right.$ films in $0.1 \mathrm{M}(\mathrm{TEA}) \mathrm{BF}_{4}$, in acetonitrile, for different potentials applied. Equivalent circuit, used for impedance spectra fitting, is presented in panel (d).
Table 1 Data on XPS analysis of [Ni(salen)], [Ni(Phazosalen)] and their polymerized forms

\begin{tabular}{lllll}
\hline Compound & $\mathrm{Ni}\left(2 \mathrm{p}_{3 / 2}\right)$ & $\mathrm{Ni}\left(2 \mathrm{p}_{1 / 2}\right)$ & $\mathrm{N}(1 \mathrm{~s})$ & $\mathrm{O}(1 \mathrm{~s})$ \\
\hline & $E_{\mathrm{b}} ; \Delta E_{\mathrm{b}}, \mathrm{eV}^{a}$ & & & \\
{$[\mathrm{Ni}($ salen$)]$} & $854.3 ;-$ & $871.5 ;-$ & $398.4 ;-$ & $530.2 ;-$ \\
{$[\mathrm{Ni}($ Phazosalen) $]$} & $854.3 ;-$ & $871.5 ;-$ & $398.6 ;-$ & $530.3 ;-$ \\
{$[\mathrm{Ni}(\text { salen })]_{n}$} & $854.9 ; 0.6$ & $872.2 ; 0.7$ & $399.1 ; 0.7$ & $530.2 ; 0.6$ \\
{$[\mathrm{Ni}(\text { Phazosalen })]_{n}$} & $854.6 ; 0.3$ & $871.9 ; 0.4$ & $398.7 ; 0.1$ & $530.2 ; 0.2$ \\
${ }^{a} \Delta E_{\mathrm{b}}=E_{\mathrm{b}}($ (polymer) & $-E_{\mathrm{b}}$ (monomer).
\end{tabular}

$[\mathrm{Ni}(\text { Phazosalen })]_{n}$ retaining more structural features of the starting monomer compared to [Ni(salen) $]_{n}$.

In addition to $\mathrm{Ni}, \mathrm{N}, \mathrm{O}$ and $\mathrm{C}(284 \mathrm{eV})$ signals, a Cl signal was also observed in the XPS spectrum of [Ni(Phazosalen) $]_{n}$ around $200 \mathrm{eV}$ (Fig. SI7, ESI†), but not in the spectrum of the starting monomer. Deconvolution of the experimental signal provided three Gaussians with maxima at 201.2, 199.7 and $197.8 \mathrm{eV}$. The last signal is typical of the chloride anion ${ }^{43}$ and could originate from the electrochemical decomposition of the solvent under experimental conditions. The first two signals are characteristic for arylchlorides, such as chlorobenzene,${ }^{44,45}$ and witness chlorination of the starting [Ni(Phazosalen)] upon electrochemical oxidation in dichloroethane. Semi-quantitative elemental analysis based on the XPS data provides the following elemental composition for the obtained material: $\mathrm{Ni}(2.0 \%), \mathrm{C}(74.9 \%), \mathrm{N}(12.5 \%)$, $\mathrm{O}(8.7 \%)$, and $\mathrm{Cl}(1.9 \%)$. This corresponds to $c a .20-30 \mathrm{~mol} \%$ of the chlorinated fragment (Table 2).

Functional group analysis of $[\mathrm{Ni}(\text { Phazosalen })]_{n}$ based on FTIR spectra confirmed that the material retains the key structural Phazosalen fragment. The band corresponding to $\mathrm{C}=\mathrm{N}$ bond stretching appears at $1637 \mathrm{~cm}^{-1}$ in the starting imine. Upon complexation with $\mathrm{Ni}^{2+}$, this band shifts to $1620 \mathrm{~cm}^{-1}$, presumably due to increased rigidity of the structure resulting from the formation of a new cycle. Subsequent oxidative transformation upon deposition of the material shows little effect on this band $\left(1624 \mathrm{~cm}^{-1}\right)$. A Ni-N valence band ${ }^{46}$ is observed in [Ni(Phazosalen)] and $[\mathrm{Ni}(\text { Phazosalen })]_{n}$ at $534 \mathrm{~cm}^{-1}$.

The NMR study of [Ni(Phazosalen)] and [Ni(Phazosalen) $]_{n}$ was performed in TFA (trifluoroacetic acid) solutions due to the solubility of these compounds in this solvent, afforded by reversible protonation of nitrogen and oxygen atoms. This study confirmed that the main component of $[\mathrm{Ni}(\text { Phazosalen })]_{n}$ is the structurally intact [Ni(Phazosalen)]. The signals in the spectrum of the starting monomeric [Ni(Phazosalen)] are widened, probably

Table 2 XPS elemental composition of [Ni(Phazosalen)] and $[\mathrm{Ni}(\text { Phazosalen })]_{n}$

\begin{tabular}{lccrrr}
\hline & \multicolumn{2}{l}{$[\mathrm{Ni}($ Phazosalen $)]$} & & \multicolumn{2}{c}{$[\mathrm{Ni}(\text { Phazosalen })]_{n}$} \\
\cline { 2 - 3 } Element & Calc. & Found & & Calc. $^{a}$ & Found \\
\hline $\mathrm{C}(1 \mathrm{~s})$ & 75.68 & 76.00 & & 74.74 & 74.93 \\
$\mathrm{~N}(1 \mathrm{~s})$ & 16.22 & 11.78 & & 16.01 & 12.53 \\
$\mathrm{O}(1 \mathrm{~s})$ & 5.41 & 10.62 & & 5.34 & 8.69 \\
$\mathrm{Ni}(2 \mathrm{p})$ & 2.7 & 1.59 & & 2.67 & 1.96 \\
$\mathrm{Cl}(2 \mathrm{p})$ & & & 1.24 & 1.89
\end{tabular}

${ }^{a}$ Calculated for $23.3 \mathrm{~mol} \%$ chlorination based on ${ }^{1} \mathrm{H}$ NMR data. 

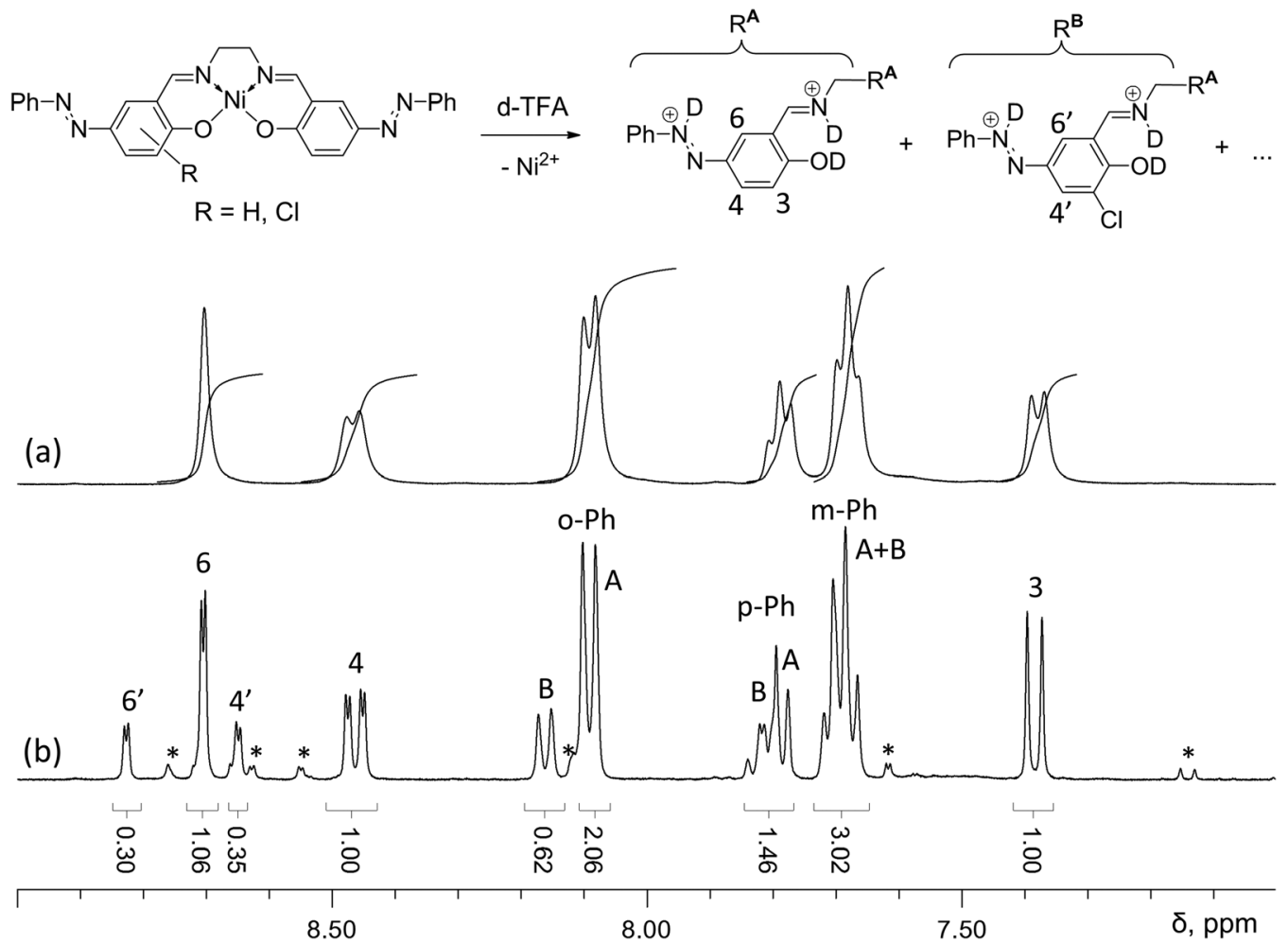

Fig. 5 Aromatic proton region in the ${ }^{1} \mathrm{H}$ NMR spectra of [Ni(Phazosalen)] (a) and [Ni(Phazosalen)] (b) solutions in d-TFA; unidentified signals of minor components are marked with an asterisk.

due to the presence of paramagnetic species. $\ddagger$ Nevertheless, the multiplicity and intensity provided unambiguous attribution. The multiplets at 8.2, 7.8 and 7.7 ppm correspond to monosubstituted phenyl rings at the azo group; the singlet at $8.7 \mathrm{ppm}$ corresponds to $\mathrm{H}^{6}$, while the $\mathrm{AB}$ system at 8.5 and $7.4 \mathrm{ppm}$ belongs to $\mathrm{H}^{3}$ and $\mathrm{H}^{4}$ (Fig. 5). These signals are better resolved in the spectrum of $[\mathrm{Ni}(\text { Phazosalen })]_{n}$ and account for $74 \mathrm{~mol} \%$ of all azo-benzene fragments. The second component (22 mol\%) shows almost the same pattern of signals, except the signal for $\mathrm{H}^{3}$, which is absent. It is possible to conclude from these data, that the minor component is a 3 -substituted derivative. Additional proof is found in the fine structure of the signals for $\mathrm{H}^{4}$ and $\mathrm{H}^{6}$, which constitute an $\mathrm{AB}$ system at 8.83 and $8.65 \mathrm{ppm}$ with a small coupling constant $J$ of $2.5 \mathrm{~Hz}$, typical for interaction of protons with meta-alignment. Combining these data with the results of XPS analysis, where chlorine atoms were observed, one can conclude that the minor component is the 3-chlorosubstituted derivative of the starting [Ni(Phazosalen)] complex. There are also trace amounts of an unidentified admixture of $c a .4 \mathrm{~mol} \%$.

Taking into account the results of XPS, FTIR and NMR analyses, we concluded that $[\mathrm{Ni}(\text { Phazosalen })]_{n}$, unlike $[\mathrm{Ni}(\text { salen })]_{n}$, represents mostly stacked molecules of monomer complex [Ni(Phazosalen)]

\footnotetext{
\# According to the works of $\mathrm{F}$. Thomas, ${ }^{31,32}$ [Ni(salen)] complexes are prone to oxidation with the formation of ligand radical species. Formation of trace amounts of such radical species might be the reason for the observed paramagnetic widening of the signals of the monomer [Ni(Phazosalen)] complex.
}

with minor inclusions of 3-chlorosubstituted derivatives (Fig. 5, $\mathrm{R}=\mathrm{Cl}$ ).

To determine the mode of stacking $(\pi-d, \pi-\pi$ or $d-d)$, we performed dispersion corrected DFT calculations (CAM-B3LYPD3/6-31G* level of theory) on possible modes of arrangement of two monomer molecules in neutral and oxidized forms.

DFT calculations were carried out for dimers comprised of [Ni(salen)] and [Ni(Phazosalen)] neutral molecules and singly charged cations. The results of geometry optimization suggest the existence of a variety of structures, differing in the relative positions of the two molecules in the dimer. Three possible stack-like structures obtained for a system containing two $[\mathrm{Ni}($ Phazosalen $)]$ molecules with a total charge of +1 are shown in Fig. 6.

For the first of these structures (Fig. 6(a)) the line connecting the nickel atoms is almost perpendicular to the NNOO-planes of the Schiff-base ligands, i.e., the two molecules are not shifted relative to each other. Though such structures can be intuitively described as dimers with d-d-stacking, electronic structure analysis does not reveal significant bonding between the nickel atoms. However, this structure is the most stable of the three dimers shown in Fig. 6; its energy of formation $(\Delta E)$ (defined as the energy of the dimer minus the energies of neutral or charged monomers) being as low as $-215 \mathrm{~kJ} \mathrm{~mol}^{-1}$. The energies of formation for two other $\left[\mathrm{Ni}(\text { Phazosalen) }]_{2}{ }^{+}\right.$structures (Fig. 6(b) and (c)) are higher by 36 and $43 \mathrm{~kJ} \mathrm{~mol}^{-1}$, respectively. In the former of these two structures, the [Ni(Phazosalen)] fragments remain almost parallel, but are shifted by about 3.2 A relative to 
(a)

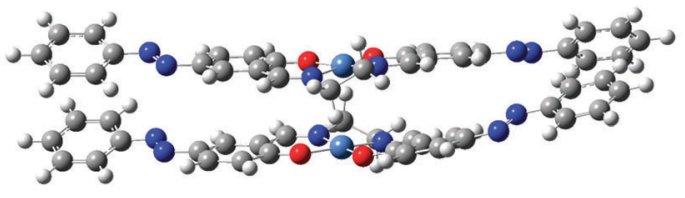

$\Delta E=-215 \mathrm{~kJ} / \mathrm{mol}$

(b)

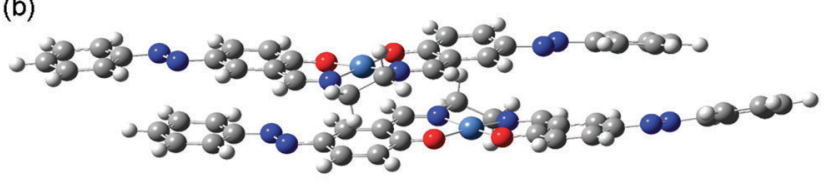

$\Delta E=-179 \mathrm{~kJ} / \mathrm{mol}$

(c)

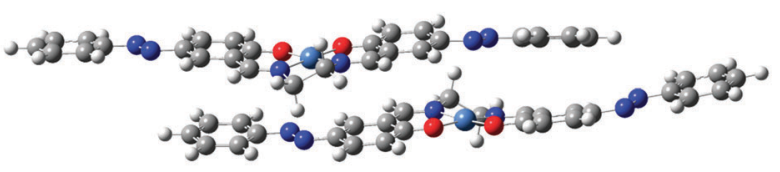

$\Delta E=-172 \mathrm{~kJ} / \mathrm{mol}$

Fig. 6 Optimized stack-like structures for $\left[\mathrm{Ni}(\text { Phazosalen) }]_{2}{ }^{+}\right.$and their energies of formation $(\Delta E)$.

each other. This shift places the nickel atoms above or below the center of the aromatic rings of the salen fragment of the neighboring molecule. Furthermore, such a configuration of the dimer can be recognized as $\pi$-d-stacking, but a more detailed insight does not show significant electron density between the metal atom and the aromatic ring. Finally, in the last of the three structures (Fig. 6(c)), the molecules are shifted by $c a$. $3.9 \AA$; hence, the nickel atoms are located over $\mathrm{N}=\mathrm{N}$ bonds without definite signs of bonding between them. Taking a closer look at the dependence of dimer stability on the shifting distance, one can observe an almost-linear change of $\Delta E$ with increasing separation of molecules. Such an effect is unlikely to be caused by differences in the nature of bonding between the molecules constituting the dimer (such as $\mathrm{d}-\mathrm{d}$ or $\pi$-d-stacking interactions); this conclusion is readily supported by electronic structure analysis.

The stability of the stack-like structures formed by [Ni(salen)] and [Ni(Phazosalen)] is strongly influenced by the total system charge and the nature of the ligand. As indicated by the computed $\Delta E$ values for 'pseudo d-d-stacked' structures similar to the one shown in Fig. 6(a), the formation of a dimer is energetically favorable only for systems with a total charge of 0 and +1 . The most stable form of both $[\mathrm{Ni}(\text { salen })]_{2}{ }^{q}$ and $[\mathrm{Ni}(\text { Phazosalen })]_{2}{ }^{q}$ dimers is the one with a total charge of +1 . The energy of formation for dimers with $q=+2$ is positive (Table 3), which is likely a result of strong Coulomb repulsion between two positively charged $[\mathrm{Ni}(\text { salen })]^{+}$or $[\mathrm{Ni}(\text { Phazosalen })]^{+}$ species. Dimers with a total charge of 0 (two neutral molecules) or +1 (one cation and one neutral molecule) are stabilized by the very large contribution of dispersion forces $\left(E_{\text {disp }}\right)$, which are represented by the Grimme's dispersion term in the density functional. This contribution is largely independent of the total charge, though it displays a small increase for oxidized dimers. The nickel-nickel distances, provided in Table 3, suggest that this effect can be explained by the decrease in the distance between
Table 3 Selected geometrical and energetic properties of [Ni(salen)] ${ }_{2}^{a}$ and $\left[\mathrm{Ni}(\text { Phazosalen) }]_{2}{ }^{q}\right.$ dimers obtained from DFT calculations

\begin{tabular}{lllll}
\hline & & \multicolumn{3}{l}{ Dimer charge $q$} \\
\cline { 3 - 5 } Dimer & Property & $q=0$ & $q=+1$ & $q=+2$ \\
\hline$[\mathrm{Ni}(\text { salen })]_{2}{ }^{q}$ & $r(\mathrm{Ni}-\mathrm{Ni}), \AA$ & 3.27 & 3.10 & 3.04 \\
& $E_{\mathrm{disp}}, \mathrm{kJ} \mathrm{mol}^{-1}$ & -225 & -232 & -232 \\
& $\Delta E, \mathrm{~kJ} \mathrm{~mol}^{-1}$ & -127 & -171 & +129 \\
& & & & \\
{$[\mathrm{Ni}(\text { Phazosalen })]_{2}{ }^{q}$} & $r(\mathrm{Ni}-\mathrm{Ni}), \AA$ & 3.28 & 3.17 & 3.17 \\
& $E_{\mathrm{disp}}, \mathrm{kJ} \mathrm{mol}^{-1}$ & -350 & -356 & -364 \\
& $\Delta E, \mathrm{~kJ} \mathrm{~mol}^{-1}$ & -158 & -215 & +34 \\
\hline
\end{tabular}

the monomers. The comparison of $\Delta E$ values for [Ni(salen)] and $[\mathrm{Ni}($ Phazosalen $)]$ shows that all forms of $[\mathrm{Ni}(\text { Phazosalen })]_{2}{ }^{q}$ dimers are significantly more stable than the equivalent $[\mathrm{Ni}(\mathrm{salen})]_{2}{ }^{q}$ species. Compared to [Ni(salen)], [Ni(Phazosalen)] dimers have significantly more negative $E_{\text {disp }}$ values. Hence, the improved stability of $[\mathrm{Ni}(\text { Phazosalen })]_{2}{ }^{q}$ species is a result of the greater contribution of dispersion interactions, which is likely to increase with increase in the area of contact between the molecules in the dimer.

The theoretical results mentioned above are consistent with $\mathrm{X}$-ray diffraction data for [Ni(salen) $]^{47}$ and [Ni(Phazosalen)] (Fig. 7).

Both these compounds are packed in a crystal in the dimeric species with a non-displaced arrangement: aryl rings atop aryl rings and metal above metal. Interestingly, the $\mathrm{Ni}-\mathrm{Ni}$ distance

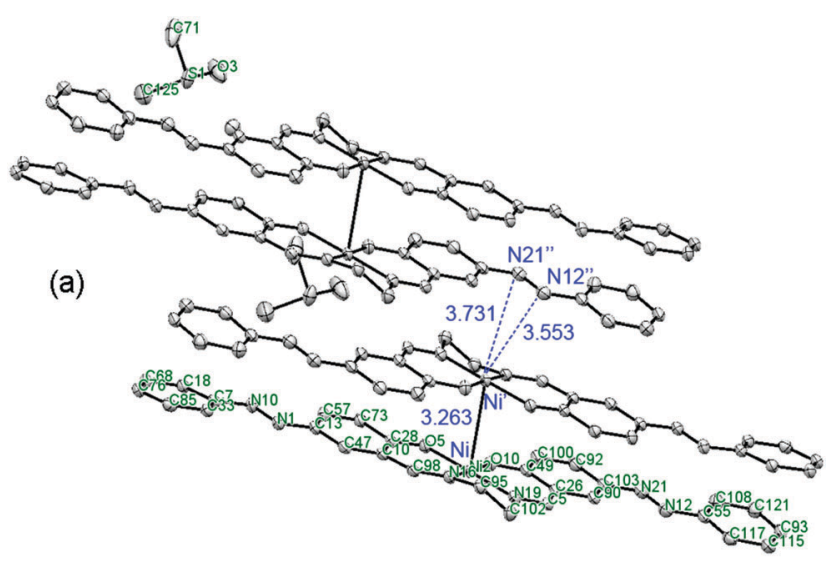

(b)

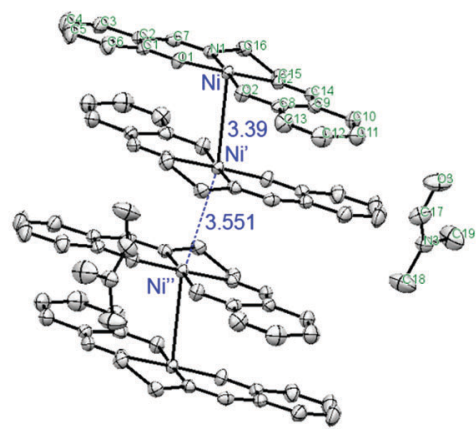

Fig. 7 Comparison of the arrangement of $[\mathrm{ML}]_{2}$ intermolecular dimers in the crystal lattice of [Ni(Phazosalen)] (this work) and [Ni(salen)]. ${ }^{47}$ 


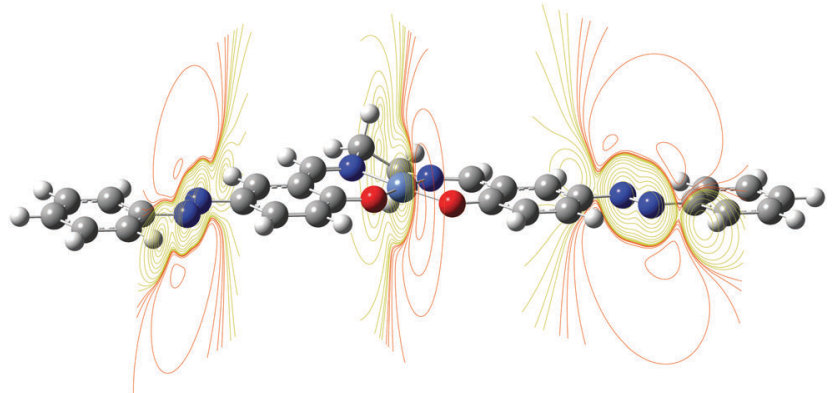

Fig. 8 Electrostatic potential slices in [Ni(Phazosalen)] complex. Regions of positive ESP are in orange color, regions of negative ESP are in purple color.

in the $[\mathrm{Ni}($ Phazosalen)] crystal is lower by $0.13 \AA$ compared to the $[\mathrm{Ni}($ salen $)]$ crystal, testifying to the existence of additional attractive intermolecular forces due to increased $\pi-\pi$ or dispersive interaction in the former case. Of special interest is the difference in the way the dimeric species are packed into the crystal in [Ni(salen)] and [Ni(Phazosalen)]. According to a literature report, ${ }^{47}$ the $[\mathrm{Ni}(\text { salen })]_{2}$ species adopt a non-displaced arrangement in a crystal, with $\mathrm{Ni}-\mathrm{Ni}^{\prime}$ distance being $c a$. $3.55 \AA$, suggesting no evidence for $\pi-\mathrm{d}$ interaction. Unlike this, the $[\mathrm{Ni}(\text { Phazosalen })]_{2}$ species are displaced parallel with respect to one another, the $\mathrm{Ni}$ atom in one dimer opposing the $\mathrm{N}=\mathrm{N}$ azo group of the adjacent dimer. The distances between $\mathrm{Ni}$ and $\mathrm{N}$ atoms are 3.55 and $3.73 \AA$, respectively. These data might be explained by Coulomb attraction of regions with positive electrostatic potential over metal atoms to the regions with negative electrostatic potential over the $\mathrm{N}=\mathrm{N} \pi$-system (Fig. 8).

Thus, $[\mathrm{Ni}(\text { Phazosalen })]_{n}$ represents a "stacked material" consisting primarily of stacked molecules of the monomer complex [Ni(Phazosalen)] rather than a classical polymer (Scheme 2). The binding forces that keep the molecules in $[\mathrm{Ni}(\text { Phazosalen })]_{n}$ together include the dispersive interaction of the extended $\pi$-systems, the Coulomb attraction of metal atoms and azo groups and the Coulomb attraction of positively charged [Ni(Phazosalen) $]^{+}$ monocations with counterions that compensate the positive charge.

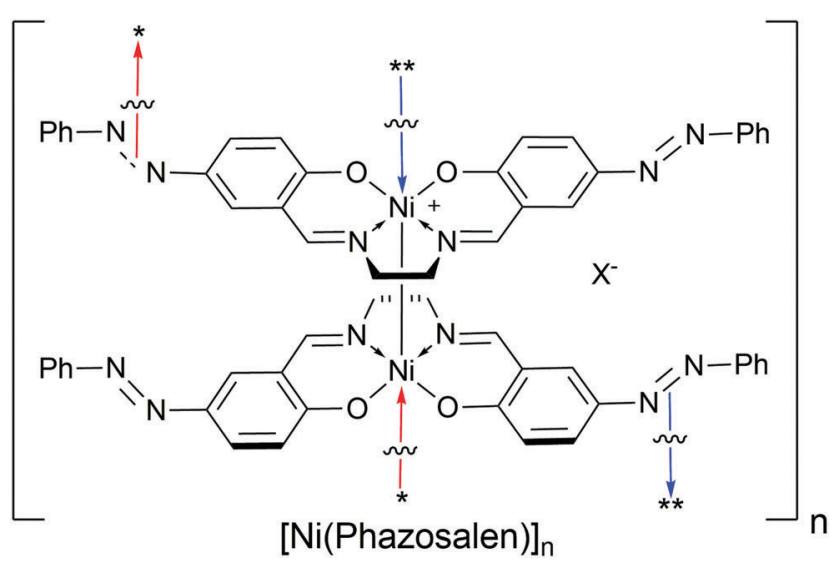

Scheme 2 Proposed structure of $\left[\mathrm{Ni}(\text { Phazosalen) }]_{n}\right.$.
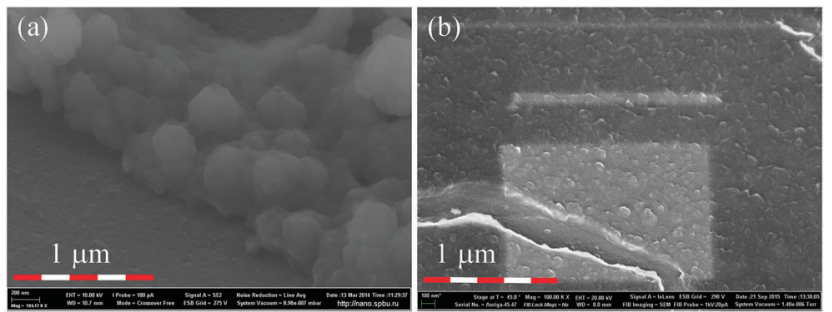

Fig. 9 SEM microphotography of $\left[\mathrm{Ni}(\text { salen) }]_{n}(\mathrm{a})\right.$ and $\left[\mathrm{Ni}(\text { Phazosalen) }]_{n}(\mathrm{~b})\right.$ films on glass carbon support.

The difference in polymer linkage nature compared to $[\mathrm{Ni}(\text { salen })]_{n}$ results in different morphology of the material. According to the SEM study of polymeric films of [Ni(salen) $]_{n}$ and $[\mathrm{Ni}(\text { Phazosalen })]_{n}$ on glass carbon support, $[\mathrm{Ni}(\text { salen })]_{n}$, having a relatively flexible organic backbone, forms a globular material with globules of ca. $300 \mathrm{~nm}$ in diameter (Fig. 9). In contrast, $[\mathrm{Ni}(\text { Phazosalen })]_{n}$, consisting of tight stacks of rigid monomers, forms a more homogenous laminated material (Fig. 9). This dense structure could be responsible for the low charge carrier diffusion coefficient observed by the impedance measurements. At the same time, the absence of $\mathrm{C}-\mathrm{C}$ bonds between the $[\mathrm{Ni}($ Phazosalen)] units indicates that, unlike $[\mathrm{Ni}(\text { salen })]_{n}$, this material does not have the long $\pi$-conjugated system. This leads to the lack of charge transport pathways, which can be responsible for high charge transfer resistance of the $[\mathrm{Ni}(\text { Phazosalen })]_{n}$ material.

Interestingly, different structure and morphology resulted in increased electrochemical stability of $[\mathrm{Ni}(\text { Phazosalen })]_{n}$ compared to $\left[\mathrm{Ni}(\text { salen) }]_{n}\right.$ in the presence of water (Fig. 10). Thus, the addition of $1 \%$ water to an acetonitrile solution of $0.1 \mathrm{M} \mathrm{Et}_{4} \mathrm{~N}^{+} \mathrm{BF}_{4}{ }^{-}$, while registering a CVA of [Ni(salen) $]_{n}$ film in the range of $0-1.2 \mathrm{~V}$, resulted in $83 \%$ activity loss (measured as the acquired charge) by the 50th cycle. On the contrary, the $[\mathrm{Ni}(\text { Phazosalen })]_{n}$ film retained full activity by the 50 th cycle. Repeating the measurement under open-to-air conditions resulted in $40.5 \%$ activity loss by the 250 th cycle for $[\mathrm{Ni}(\text { Phazosalen })]_{n}$; this is an excellent result for [Ni(salen)]-based materials, which are known to be moisture sensitive. ${ }^{16,17}$

In $0.1 \mathrm{M} \mathrm{LiClO}_{4}$ aqueous solution, there is no loss of activity for $[\mathrm{Ni}(\text { Phazosalen })]_{n}$ film in the potential range from 0 to $1.2 \mathrm{~V}$ (Fig. 10c and Fig. SI3a, ESI $\dagger$ ). After increasing it to $1.3 \mathrm{~V}$, the film loses only $9.5 \%$ of the initial activity by the 50 th cycle (Fig. SI3b, ESI $\dagger$ ). An increase of the upper boundary of the potential range to $1.4 \mathrm{~V}$ resulted in the quick loss of electrochemical activity by the film.

The observed moisture resistance of $[\mathrm{Ni}(\text { Phazosalen })]_{n}$ can be used for the creation of moisture resistant energy storage devices based on aqueous electrolytes, as well as other waterbased devices such as electrochemical sensors. The specific capacitance of $[\mathrm{Ni}(\text { Phazosalen })]_{n}$ polymer material was determined by QCM measurements to be $120 \mathrm{~F} \mathrm{~g}^{-1}$. Although this value is two times less than the specific capacitance of [Ni(salen) $]_{n}$ due to the higher molecular weight of the [Ni(Phazosalen)] fragment, the superior stability of the new material is a substantial advantage. 

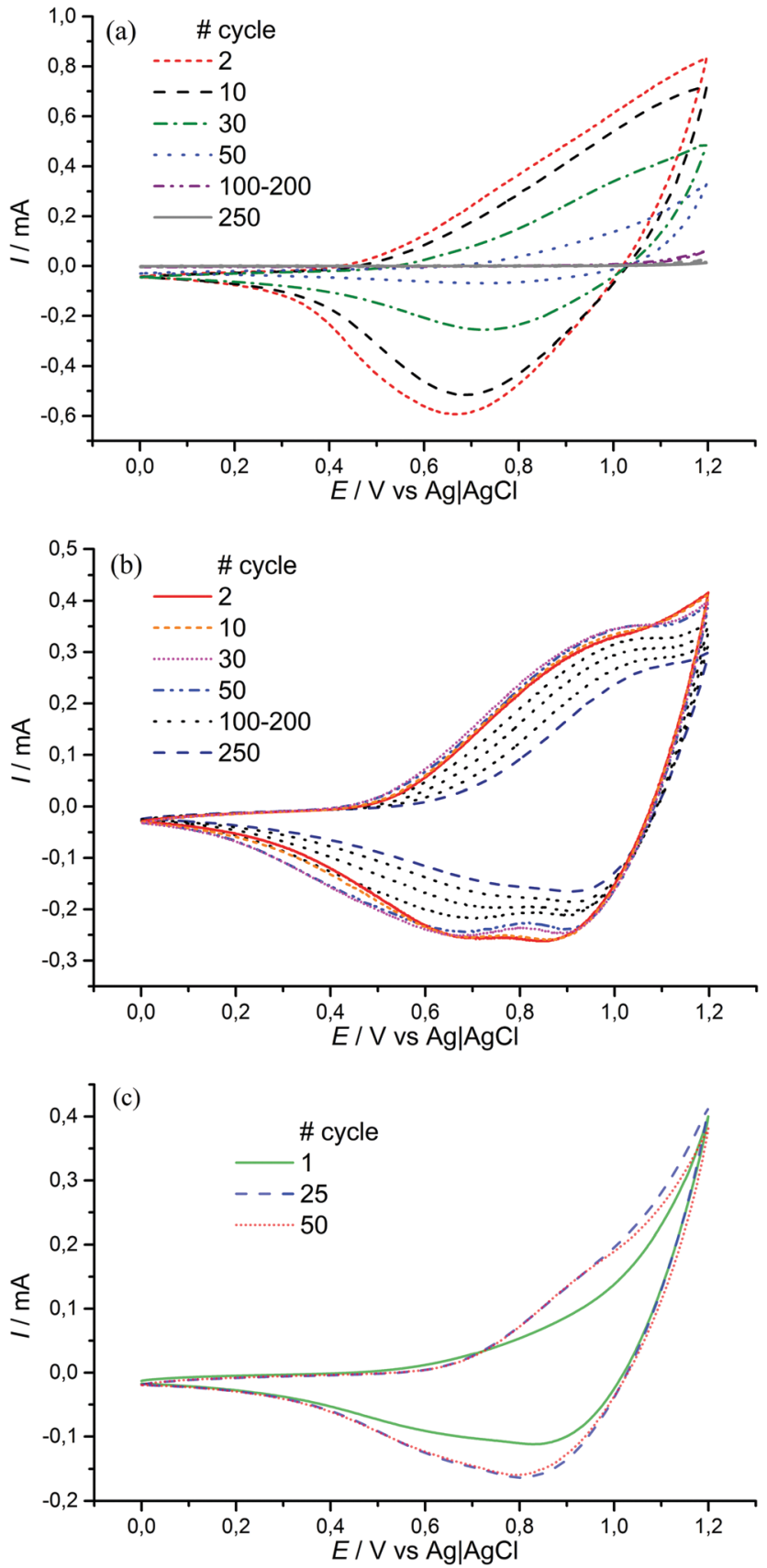

Fig. $10 \mathrm{CVA}$ of [Ni(salen) $]_{n}$ film (a) and [Ni(Phazosalen) $]_{n}$ film (b) in MeCN/ 1 wt\% $\mathrm{H}_{2} \mathrm{O}$ solution of $0.1 \mathrm{M} \mathrm{Et}_{4} \mathrm{~N}^{+} \mathrm{BF}_{4}{ }^{-}$as the supporting electrolyte; CVA of $\left[\mathrm{Ni}(\text { Phazosalen) }]_{n}\right.$ film in $0.1 \mathrm{M}$ aqueous solution of $\mathrm{LiClO}_{4}$ as the supporting electrolyte (c), scan rate $-50 \mathrm{mv} \mathrm{s}^{-1}$.

\section{Conclusions}

To conclude, we have synthesized a new electrode material from the [Ni(salen)] family. The material bears phenylazogroup in the $p$-position with respect to the oxygen atom in the salenligand core, preventing the usual polymerization of [Ni(salen)] complexes via oxidative coupling of the phenyl rings. Instead, the complex molecules are held together by dispersive and ionic interactions. The material obtained exhibits excellent moisture resistance and can be applied in the creation of water resistant electrode materials for energy storage or sensor applications.

\section{Experimental}

\section{Materials and methods}

Materials. Commercial $\mathrm{Bu}_{4} \mathrm{NBF}_{4}, \mathrm{LiClO}_{4}$, acetonitrile, 1,2-dichloroethane and DMSO were used without further purification. The phazosalen ligand and the [Ni(Phazosalen)] complex were synthesized according to known procedures. ${ }^{37}$

$[\mathrm{Ni}(\text { Phazosalen })]_{n}$ was electrochemically deposited from $1 \mathrm{mM}$ solution [Ni(Phazosalen)] in $0.1 \mathrm{M}$ solution $\mathrm{Bu}_{4} \mathrm{NBF}_{4}$ in 1,2-dichloroethane. Electrochemical deposition was performed in a three-electrode cell on ITO or glass-carbon support as a working electrode, Pt plate as a counter electrode and BASi MF-2062 Ag $\mid \mathrm{Ag}^{+}$(Ag wire immersed in acetonitrile containing $0.1 \mathrm{M} \mathrm{AgNO}_{3}$ ) as a reference electrode. The potential of the latter was found to comprise $+0.40 \mathrm{~V}$ vs. $\mathrm{Ag} \mid \mathrm{AgCl}$ (aqueous saturated $\mathrm{KCl}$ ) reference electrode. All potentials throughout the text are recalculated $v s$. an aqueous $\mathrm{Ag} \mid \mathrm{AgCl}$ electrode. The deposition was realized in potentiostatic mode with an applied bias of $1.2 \mathrm{~V}$. The bias was applied until the consumption of $57 \mathrm{mC} \mathrm{cm}^{-2}$ was achieved.

General methods. FTIR were recorded in $\mathrm{KBr}$ tablets. ${ }^{1} \mathrm{H}$ NMR spectra were recorded in $\mathrm{CF}_{3} \mathrm{CO}_{2} \mathrm{D}$; the chemical shifts are reported in ppm downfield from $\left(\mathrm{CH}_{3}\right)_{4} \mathrm{Si}$. Single-crystal $\mathrm{X}$-ray diffraction experiments were performed on a diffractometer at $100 \mathrm{~K}$ using monochromated $\mathrm{CuK} \alpha$ radiation.

Electrochemical studies. The electrochemical properties of the obtained electrode materials were studied in a $0.1 \mathrm{M}$ acetonitrile solution of $\mathrm{Bu}_{4} \mathrm{NBF}_{4}$ as the supporting electrolyte or in a $0.1 \mathrm{M}$ aqueous solution of $\mathrm{LiClO}_{4}$. A glass-carbon electrode $\left(S 0.07 \mathrm{~cm}^{2}\right)$ or an ITO-coated electrode $\left(S 0.5-2.0 \mathrm{~cm}^{2}\right)$ was used for CVA measurements. A Pt-coated crystalline-quartz electrode $\left(S 1.37 \mathrm{~cm}^{2}\right.$ ) was used for microgravimetric analysis. A scan rate of $50 \mathrm{mv} \mathrm{s}^{-1}$ was used in all CVA experiments.

XPS measurements. XPS spectra were recorded using a Thermo Fisher Scientific Escalab 250Xi spectrometer with nonmonochromatic $\mathrm{AlK}_{\alpha}$ radiation (photon energy $1486.6 \mathrm{eV}$ ). The samples for measurements were deposited on platinum foil. The total energy resolution of the experiment was about $0.3 \mathrm{eV}$.

Spectra of the samples were recorded in the constant pass energy mode at $20 \mathrm{eV}$, using a 650 micron diameter analysis area. During data processing of the XPS spectra, the binding energy values were referenced to the $\mathrm{C} 1 \mathrm{~s}$ peak $(284.8 \mathrm{eV})$ from the adventitious contamination layer. Investigations were carried out at room temperature in an ultrahigh vacuum of the order of $1 \times 10^{-9}$ mbar. The AVANTAGE software package was used for acquisition and data analysis.

Crystallography. The single-crystal of [Ni(Phazosalen)] was grown from a saturated DMSO solution as red needles of the solvate complex [ $\mathrm{Ni}($ Phazosalen) $] \cdot \mathrm{DMSO} \cdot 0.8 \mathrm{H}_{2} \mathrm{O}$. Moiety formula: $\mathrm{C}_{28} \mathrm{H}_{22} \mathrm{~N}_{6} \mathrm{NiO}_{2}, \mathrm{C}_{2} \mathrm{H}_{6} \mathrm{O}, 0.8\left(\mathrm{H}_{2} \mathrm{O}\right)$. Crystalline system: monoclinic; space group: $P 121 / c 1 ; \quad a / \AA$ 9.5639(5), $\quad b / \AA$ 29.9290(12), $c / \AA$ 
10.7888(5); $\beta /$ deg. 116.105(6); $U / \AA^{3} 2773.2(3) ; Z 4 ; \mu / \mathrm{mm}^{-1}$ 2.109. The complete description is given in the CIF-file in the $\mathrm{ESI} \dagger$ package.

Quantum chemical calculations. DFT calculations were carried out using the Gaussian 09 software package ${ }^{48}$ with long-rangeand dispersion-corrected CAM-B3LYP-D3 functional. ${ }^{49,50}$ The LANL2DZ effective core potential and basis set ${ }^{51}$ were chosen for nickel atoms and the Pople-type 6-31G(d) basis set for all other atoms. Basis set superposition errors were treated using the BoysBernardi counterpoise correction. ${ }^{52}$ GaussView 5.0 software $^{53}$ was used to visualize the results of DFT calculations.

Unconstrained geometry optimizations were carried out for dimers consisting of two [Ni(salen)] or [Ni(Phazosalen)] complexes; the optimized structures were verified by vibrational frequency analysis.

\section{Conflicts of interest}

There are no conflicts to declare.

\section{Acknowledgements}

The work was supported by the Russian Science Foundation (grant \#16-13-00038). Scientific research was partially performed at the Research park of St. Petersburg State University: Interdisciplinary Center for Nanotechnology, Center for Chemical Analysis and Materials Research, Chemistry Educational Centre, Magnetic Resonance Research Centre, Centre for X-ray Diffraction Studies, Computing Centre X-ray Diffraction Studies, Computing Centre, Center for Studies in Surface Science.

\section{Notes and references}

1 F. Gao, J. Li, F. Kang, Y. Zhang, X. Wang, F. Ye and J. Yang, J. Phys. Chem. C, 2011, 115, 11822.

2 M. P. Karushev and A. M. Timonov, Russ. J. Appl. Chem., 2012, 85, 914.

3 J. L. Li, F. Gao, Y. K. Zhang, F. Y. Kang, X. D. Wang, F. Ye and J. Yang, Sci. China: Chem., 2012, 55, 1338.

4 J. Tedim, F. Goncalves, M. F. R. Pereira, J. L. Figueiredo, C. Moura, C. Freire and A. R. Hillman, Electrochim. Acta, 2008, 53, 6722 .

5 Y. Zhang, J. Li, F. Gao, F. Kang, X. Wang, F. Ye and J. Yang, Electrochim. Acta, 2012, 76, 1.

6 G. Yan, J. Li, Y. Zhang, F. Gao and F. Kang, J. Phys. Chem. C, 2014, 118, 9911.

7 J. Tedim, R. Bessada, S. Patricio, A. L. Magalhaes, C. Freire, S. J. Gorman and A. R. Hillman, Langmuir, 2008, 24, 8998.

8 O. F. Filho, E. R. Dockal, L. Humberto, M. Junior and M. F. S. Teixeira, Anal. Lett., 2007, 40, 1825.

9 C. S. Martin, T. R. L. Dadamos and M. F. S. Teixeira, Sens. Actuators, B, 2012, 175, 111.

10 V. T. Avanesyan and M. Y. Puchkov, Phys. Solid State, 2009, 51, 2178.
11 S. A. Krasikova, M. A. Besedina, M. P. Karushev, E. A. Dmitrieva and A. M. Timonov, Russ. J. Electrochem., 2010, 46, 218.

12 M. Nunes, M. Araujo, J. Fonseca, C. Moura, R. Hillman and C. Freire, ACS Appl. Mater. Interfaces, 2016, 8, 14231.

13 L. Gomes, C. Sousa, C. Freire and B. de Castro, Acta Crystallogr., Sect. C: Cryst. Struct. Commun., 2000, 56, 1201.

14 M. Vilas-Boas, I. C. Santos, M. J. Henderson, C. Freire, A. R. Hillman and E. Vieil, Langmuir, 2003, 19, 7460.

15 J. Tedim, A. Carneiro, R. Bessada, S. Patricio, A. L. Magalhaes, C. Freire, S. J. Gurman and A. R. Hillman, J. Electroanal. Chem., 2007, 610, 46.

16 P. Audebert, P. Capdevielle and M. Maumy, New J. Chem., 1992, 16, 697.

17 C. S. Martin, C. Gouveia-Caridade, F. N. Crespilho, C. J. L. Constantino and C. M. A. Brett, Electrochim. Acta, 2015, 178, 80.

18 I. A. Chepurnaya, P. V. Gaman'kov, T. Yu. Rodyagina, S. V. Vasil'eva and A. M. Timonov, Russ. J. Electrochem., 2003, 39, 314 .

19 S. V. Vasil'eva, K. P. Balashev and A. M. Timonov, Elektrokhimiya, 1998, 34, 1090.

20 M. P. Karushev, Mechanisms of polymerization and charge transport in polymer complexes of nickel with Schiff bases, $\mathrm{PhD}$ thesis, Herzen State Pedagogical University of Russia, St. Petersburg, 2012.

21 K. A. Goldsby, J. K. Blaho and L. A. Hoferkamp, Polyhedron, 1989, 8, 113.

22 J. Tedim, S. Patrício, J. Fonseca, A. L. Magalhães, C. Moura, A. R. Hillman and C. Freire, Synth. Met., 2011, 161, 680.

23 M. Vilas-Boas, C. Freire, B. De Castro, P. A. Christensen and A. R. Hillman, Inorg. Chem., 1997, 36, 4919.

24 C. E. Dahm, D. G. Peters and J. Simonet, J. Electroanal. Chem., 1996, 410, 163.

25 G. Shagisultanova, I. Orlova, L. Ardasheva and E. Popova, Macromol. Symp., 1998, 136, 91.

26 M. Martins, M. Vilas-Boas, B. de Castro, A. R. Hillman and C. Freire, Electrochim. Acta, 2005, 51, 304.

27 P.-H. Aubert, A. Neudeck, L. Dunsch, P. Audebert, P. Capdevielle and M. Maumy, J. Electroanal. Chem., 1999, 470, 77.

28 M. Vilas-Boas, M. J. Henderson, C. Freire, A. R. Hillman and E. Vieil, Chem. - Eur. J., 2000, 6, 1160.

29 M. Vilas-Boas, C. Freire, B. De Castro, P. A. Christensen and A. R. Hillman, Chem. - Eur. J., 2001, 7, 139.

30 B. Bag, N. Mondal, G. Rosair and S. Mitra, Chem. Commun., $2000,1729$.

31 O. Rotthaus, O. Jarjayes, F. Thomas, C. Philouze, C. P. D. Valle, E. Saint-Aman and J. L. Pierre, Chem. - Eur. J., 2006, 12, 2293.

32 O. Rotthaus, F. Thomas, O. Jarjayes, C. Philouze, E. SaintAman and J. L. Pierre, Chem. - Eur. J., 2006, 12, 6953.

33 L. A. Hoferkamp and K. A. Goldsby, Chem. Mater., 1989, 1, 348. 34 T. Storr, E. C. Wasinger, E. C. Pratt and R. C. Stack, Angew. Chem., Int. Ed., 2007, 46, 5198.

35 R. M. Clarke, K. Herasymchuk and T. Storr, Coord. Chem. Rev., 2017, 352, 67. 
36 Y. Shimazaki, F. Tani, K. Fukui, Y. Naruta and O. Yamauchi, J. Am. Chem. Soc., 2003, 125, 10512.

37 W.-S. Han, H.-J. Lee, J.-S. Lee, Y.-H. Lee and T.-K. Hong, J. Anal. Chem., 2014, 69, 187.

38 L. P. Ardasheva, G. V. Vovk, L. G. Pchelova and G. A. Shagisultanova, Russ. J. Appl. Chem., 2004, 77, 1962.

39 Z. Q. Gao, C. Kvarnström and A. Ivaska, Electrochim. Acta, 1994, 39, 1419.

40 O. V. Levin, M. P. Karushev, A. M. Timonov, E. V. Alekseeva, Sh. Zhangac and V. V. Malev, Electrochim. Acta, 2013, 109, 153.

41 L. J. Matienzo, L. I. Yin, S. O. Grim and W. E. Swartz, Inorg. Chem., 1973, 12, 2762.

42 L. Chiang, K. Herasymchuk, F. Thomas and T. Storr, Inorg. Chem., 2015, 54, 5970.

43 H. Konno and Y. Yamamoto, Bull. Chem. Soc. Jpn., 1987, 60, 2561.

44 D. T. Clark, D. Kilcast and W. K. R. Musgrave, J. Chem. Soc. D Chem. Commun., 1971, 516b.

45 D. T. Clark, D. Kilcast, D. B. Adams and W. K. R. Musgrave, J. Electron Spectrosc. Relat. Phenom., 1975, 6, 117.

46 J. Liu, B. Wu, B. Zhang and Y. Liu, Turk. J. Chem., 2006, 30, 41.

47 M. Lutz, Acta Crystallogr., Sect. E: Struct. Rep. Online, 2003, 59, 950.

48 M. J. Frisch, G. W. Trucks, H. B. Schlegel, G. E. Scuseria, M. A. Robb, J. R. Cheeseman, G. Scalmani, V. Barone,
G. A. Petersson, H. Nakatsuji, X. Li, M. Caricato, A. Marenich, J. Bloino, B. G. Janesko, R. Gomperts, B. Mennucci, H. P. Hratchian, J. V. Ortiz, A. F. Izmaylov, J. L. Sonnenberg, D. Williams-Young, F. Ding, F. Lipparini, F. Egidi, J. Goings, B. Peng, A. Petrone, T. Henderson, D. Ranasinghe, V. G. Zakrzewski, J. Gao, N. Rega, G. Zheng, W. Liang, M. Hada, M. Ehara, K. Toyota, R. Fukuda, J. Hasegawa, M. Ishida, T. Nakajima, Y. Honda, O. Kitao, H. Nakai, T. Vreven, K. Throssell, J. A. Montgomery, Jr., J. E. Peralta, F. Ogliaro, M. Bearpark, J. J. Heyd, E. Brothers, K. N. Kudin, V. N. Staroverov, T. Keith, R. Kobayashi, J. Normand, K. Raghavachari, A. Rendell, J. C. Burant, S. S. Iyengar, J. Tomasi, M. Cossi, J. M. Millam, M. Klene, C. Adamo, R. Cammi, J. W. Ochterski, R. L. Martin, K. Morokuma, O. Farkas, J. B. Foresman and D. J. Fox, Gaussian 09, Revision E.01, Gaussian, Inc., Wallingford CT, 2015.

49 T. Yanai, D. Tew and N. Handy, Chem. Phys. Lett., 2004, 393, 51.

50 S. Grimme, J. Antony, S. Ehrlich and H. Krieg, J. Chem. Phys., 2010, 132, 154104.

51 P. J. Hay and W. R. Wadt, J. Chem. Phys., 1985, 82, 299.

52 S. F. Boys and F. Bernardi, Mol. Phys., 1970, 19, 553.

53 R. D. Dennington II, T. A. Keith and J. M. Millam, GaussView, Version 5.0.9, Semichem Inc., Shawnee Mission, KS, 2009. 